\title{
Main hydrographic features of the Sargasso Sea in Spring 1979
}

\author{
G. Wegner \\ Deutsches Hydrographisches Institut; Bernhard-Nocht-Straße 78, D-2000 Hamburg, \\ Federal Republic of Germany
}

\begin{abstract}
Hydrographic data for the period 19th March to 16th April 1979, obtained from cruise No. 210/92 of F.R.V. "Anton Dohrn" in the Sargasso Sea, are used for a description of the different water masses. Horizontal and vertical distributions are discussed, stressing the layering in particular. The regional differences of the t-S correlations are shown, especially the slight differences characterizing the deeper water masses. Dynamic computations lead to some conclusions concerning the influence of hydrographic features upon the 0-group eel larvae.
\end{abstract}

\section{INTRODUCTION}

During the second part of cruise 210/92 of the F.R.V. "Anton Dohrn" - from 19th March 1979 to 9th May 1979 - hydrographic data were obtained as background information to the samples collected by the different biological working groups as described by Tesch (1982).

The Stations 1 to $264^{*}$ on the North-South and East-West sections (Fig. 1) were carried out during the period from 19th March to 16th April 1979. Temperature and conductivity/salinity data were gathered, using CTD (Kiel Multisonde, calibrated with reference Nansen bottle), XBT, and a continuous temperature and salinity recorder at a depth of $5 \mathrm{~m}$.

Depending upon the maximum biological sampling depth, the CTD was always used down to at least $600 \mathrm{~m}$. With only slight failures, the XBTs recorded down to about $250 \mathrm{~m}, 500 \mathrm{~m}$, or $900 \mathrm{~m}$ corresponding to the probe types. Thus, except for 7 biological stations which were close to the following hydrographic station, at least one vertical temperature profile through the surface layer - down to $250 \mathrm{~m}$ - was taken at each station during this part of the cruise. The 59 CTD stations are marked by filled circles in Figure 1. This Figure also contains the positions of the hydrographic station work of R.V. "Friedrich Heincke". The XBT and Nansen bottle data are partly incomplete, owing to the priority of the biological programme. They are used for the compilation of the horizontal $\mathrm{t}_{\mathrm{r}} \mathrm{S}$, and $\sigma(\mathrm{t}, \mathrm{S})^{* *}$ distributions given.

" Hydrographical counting: Station 1 corresponds to "Anton Dohrn" Station 5505, Station 264 to 5768 .

** Symbols and units of the physical quantities correspond to the Sun Report, IAPSO Publication scientifique No 31,1979 . S: salinity in $10^{3}$ (formerly in \%), $\sigma$ : density index in $(\mathrm{g}-1) \times 10^{3}$. 


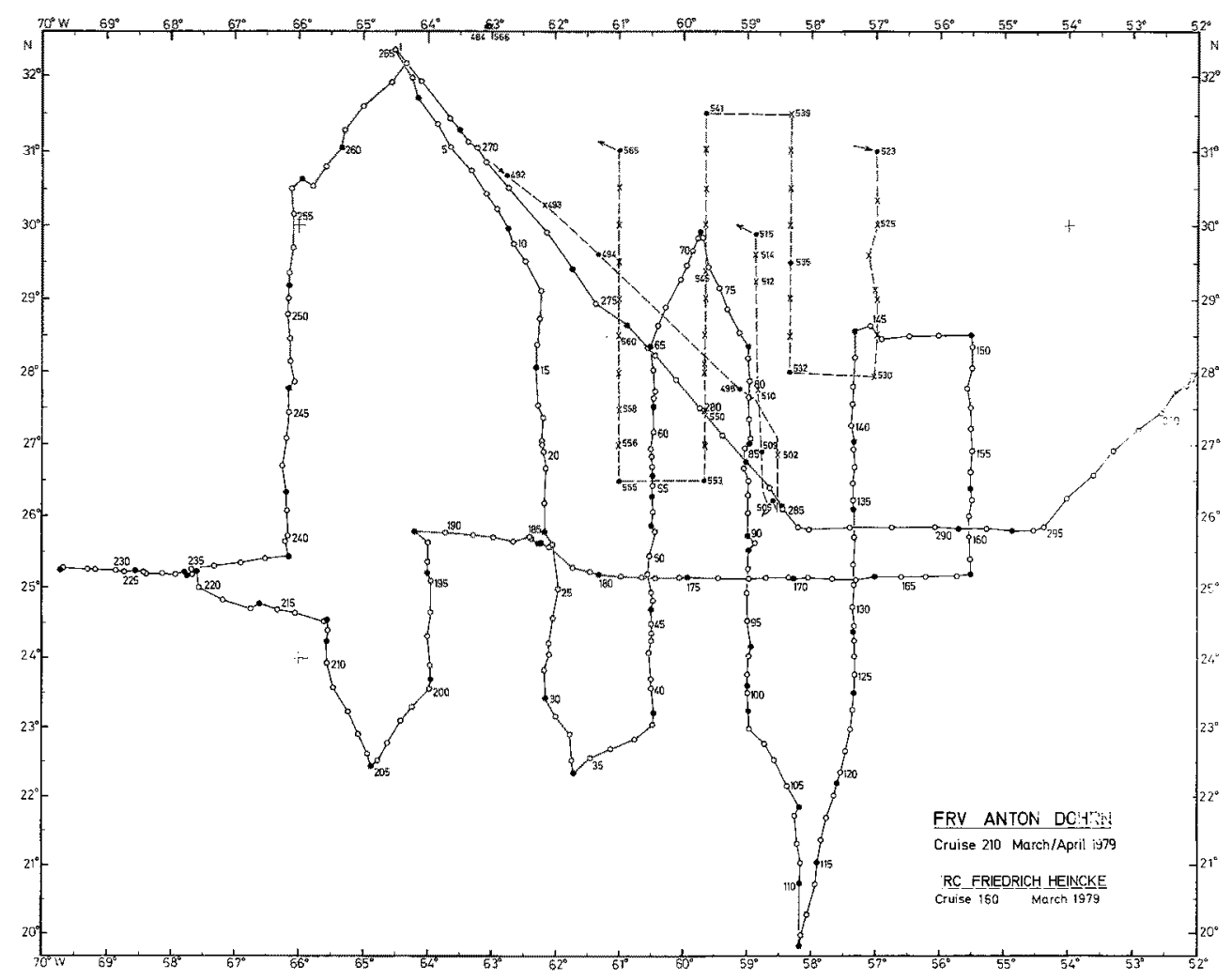

Fig. 1. Track of F.R.V. "Anton Dohrn" and section of track of R.V. "Friedrich Heincke"

The hydrographic data of the "Anton Dohrn" course back to Bremerhaven collected with the same instruments - was only partly taken into account. Spatial and temporal variations of the subtropical convergence provided a lot of difficulties when combining them with earlier data. Thus, the following description of the mean hydrographic features is based upon the data of the period 19th March to 16th April 1979. This paper - maybe not extensive enough for "pure" oceanographers - may help biologists to obtain an idea of some of the physical processes involved.

\section{Horizontal $t, S$, and $\sigma(t, S)$ distributions}

The horizontal distributions of temperature, salinity, and density index in the surface layer are given in Figures $2 a-c$. To exclude the diurnal variation of temperature in this calm weather area, Figure 2a shows the temperatures measured at a depth of $5 \mathrm{~m}$. The salinities recorded at the same depth (Fig. 2b) were equal to those at the surface. Of course, Figures $2 \mathrm{a}-\mathrm{c}$ do not show a synoptic situation. The time delay concealed in these charts is about 4 weeks, as already mentioned. According to Canadian SST charts, the local change of surface temperatures in the northern part of the area investigated was more than $2 \mathrm{~K}$ within a week. Thus, only the general features of Figures $2 \mathrm{a}-\mathrm{c}$ can be discussed. 


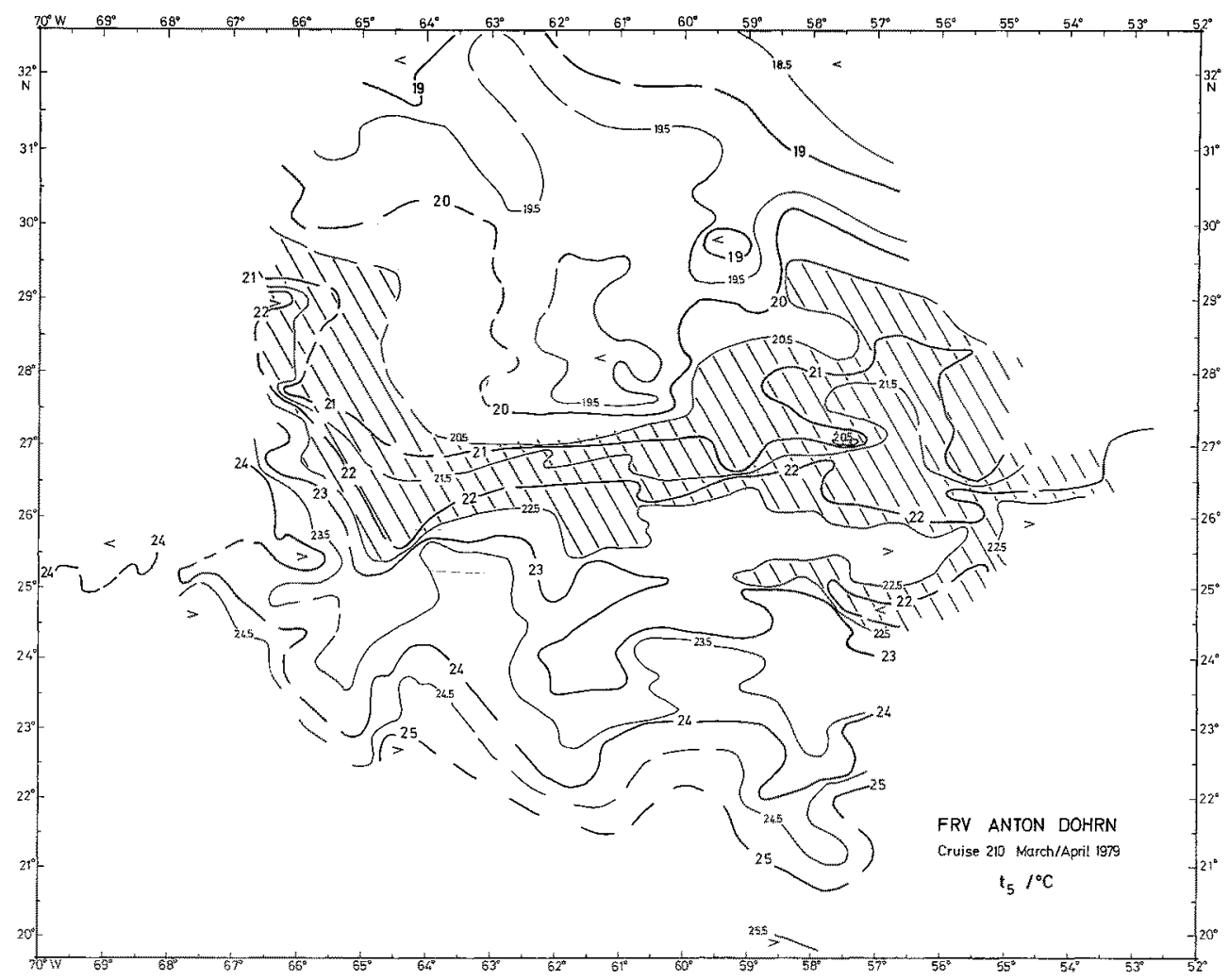

Fig. 2a. Temperature distribution in $5 \mathrm{~m}$ depth (hatched; mixing zone)

The northern part of the area investigated was characterized by water masses with very slight horizontal gradients. The temperature, salinity, and density index ranges were $18.6^{\circ} \mathrm{C}$ to $20.5^{\circ} \mathrm{C}, 36.5 \times 10^{-3}$ to $37.0 \times 10^{-3}$, and 25.7 to 26.3 respectively. To the south and west, this water, almost completely homogeneous down to $150 \mathrm{~m}$ (Fig. 5) - in its northernmost part "eighteen degrees" water (Istoshin, 1961), - was bordered by the subtropical convergence. This more or less extended mixing zone (hatched in Fig. 2) contained the temperature range of $20.5^{\circ} \mathrm{C}$ to $22.5^{\circ} \mathrm{C}$, salinities of $36.7 \times 10^{-3}$ to $37.1 \times$ $10^{-3}$, and density indices of 25.4 to 26.0 . A third surface water mass, south and west of the convergence, had increasing temperatures and decreasing salinities and density indices. Towards the south and west, at the perimeter of the Antilles Current, the horizontal $t$ increase and $S$ and $\sigma$ decrease became stronger. Apart from the northernmost area, there was no constant $\mathrm{t}-\mathrm{S}$ correlation of the surface waters (see Fig. 7). Deducing meanders or eddies from the given surface distributions without taking into account any other sources is dubious. The spatial and temporal distances during this biological survey were too large for such attempts. Certainly, "Anton Dohrn" crossed eddies and/or meanders of the subtropical convergence at different times. Difficulties in getting a vertical wire when lowering the CTD, and the recorded sudden jumps in trawling depth 


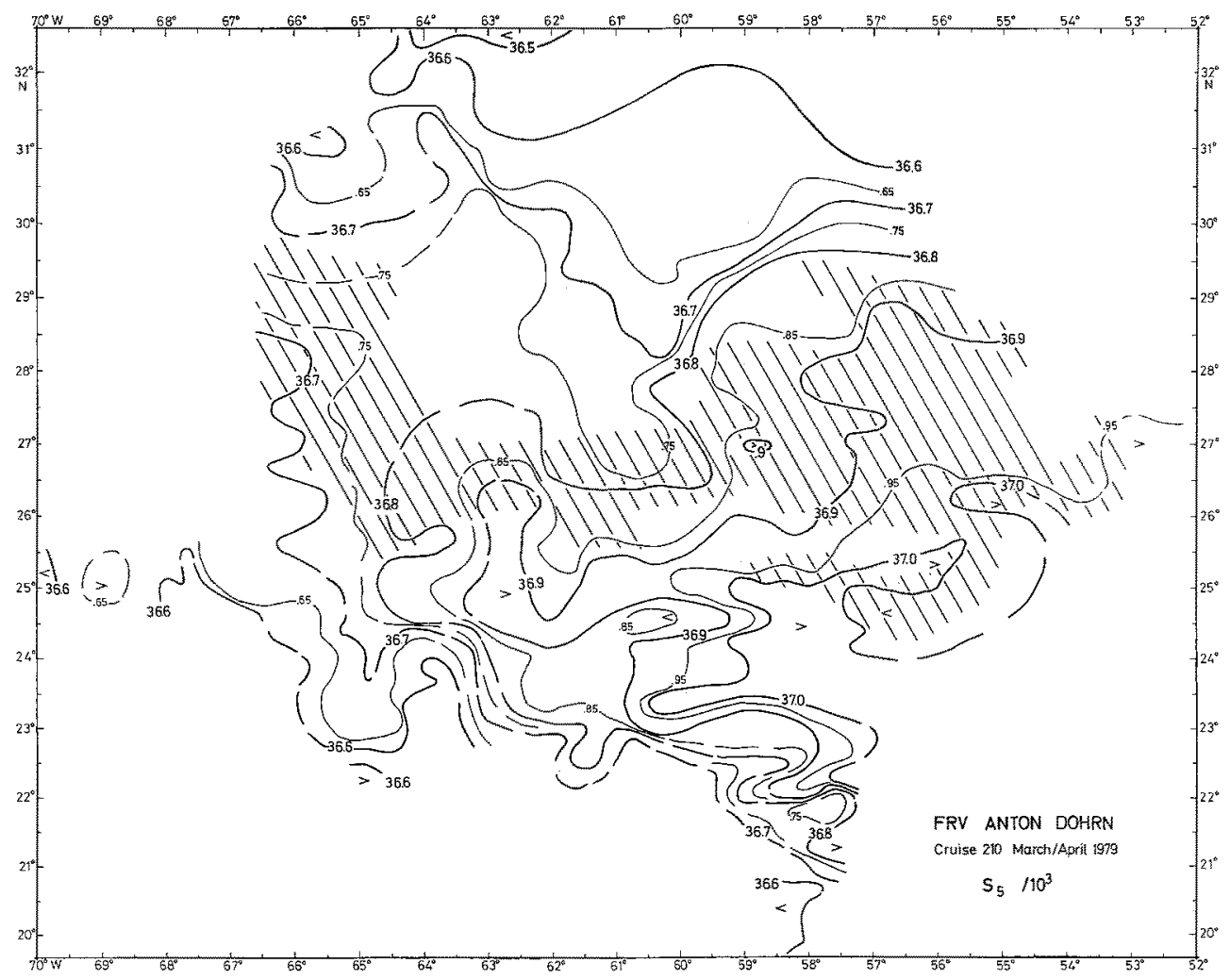

Fig. 2b. Salinity distribution in $5 \mathrm{~m}$ depth (hatched: mixing zone)

and current velocities of the MOCNESS are explainable not only by the eccentricities of the Bermuda Triangle, but also by such strong water mass movements as are connected with eddies or meanders. One deep-reaching cold core counterclockwise eddy of about $100 \mathrm{~km}$ diameter (or a pronounced meander) was met with twice, centred at Stations 224 and $230\left(25^{\circ} 12^{\prime} \mathrm{N}, 68^{\circ} 40^{\circ} \mathrm{W}\right)$. In the surface distributions, it was masked. In the Figures $3 a-c$ and in Figure 6 , it is to be seen in the westernmost part of the area investigated. Furthermore, this feature was found in the area where Beckerle (1972) supposed the existence of a stable eddy street.

A partly better impression of the upper water zones investigated is given in Figures $3 a-c$ which show temperatures, salinities, and density indices in $100 \mathrm{~m}$ depth. This depth was chosen because it seems to be the mean depth of the maximum larvae catches (Schoth \& Tesch, 1982). The temperature distribution (Fig. 3a) especially provides a good idea of the different areas shown in Figure 2. The convergence area was much more pronounced in $100 \mathrm{~m}$ depth by the $21^{\circ} \mathrm{C}$ and $22^{\circ} \mathrm{C}$ isotherms. They were running close together as frontal zones through a large part of the area investigated. To the south, an area with a fixed temperature range $\left(22{ }^{\circ} \mathrm{C}\right.$ to $\left.23^{\circ} \mathrm{C}\right)$ followed. Remarkable increases in temperatures first occurred at the perimeter of the Antilles Current. 


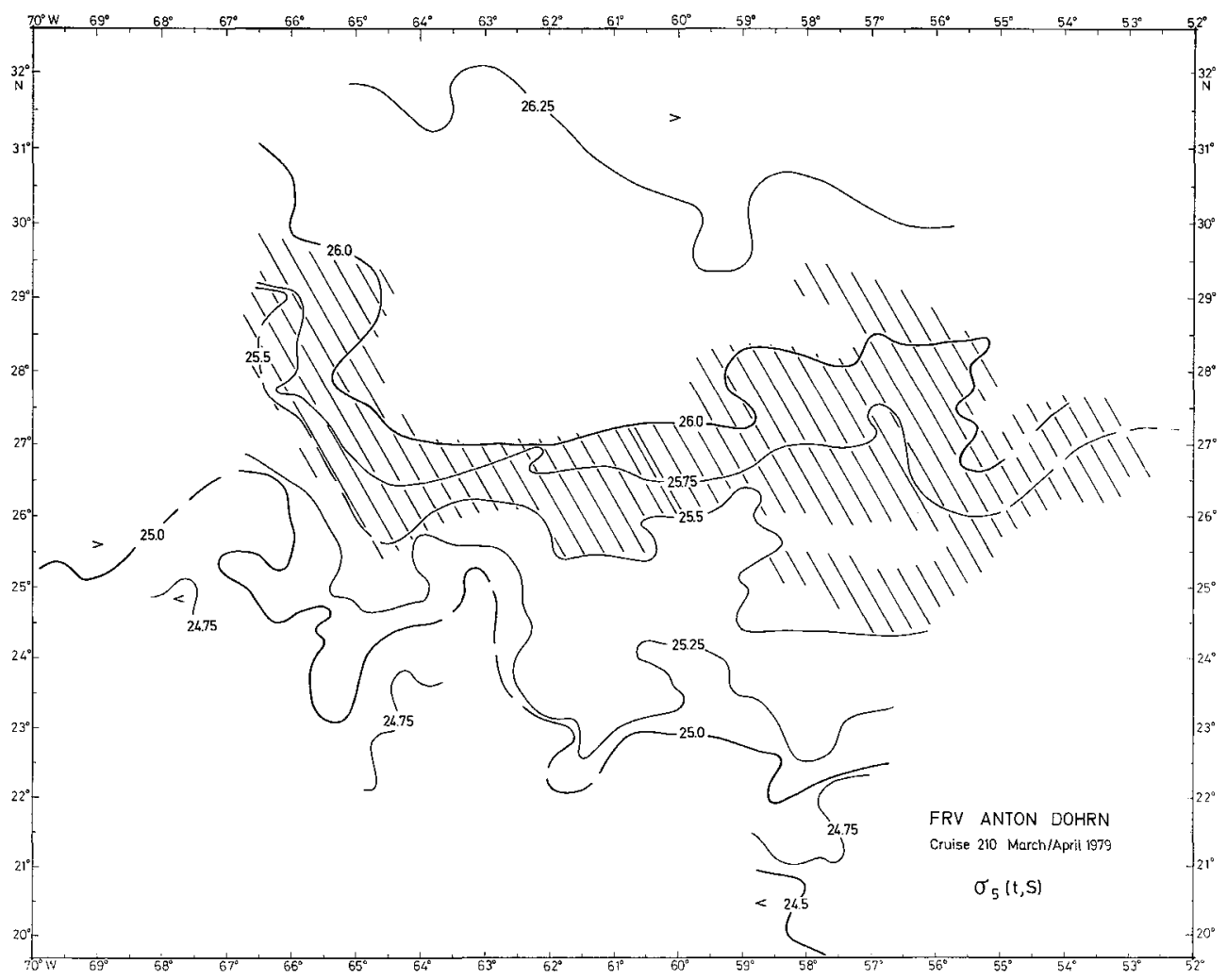

Fig. 2c. Density index distribution in $5 \mathrm{~m}$ depth (hatched: mixing zone)

On the other hand, the salinity distribution in this depth (Fig. 3b) gave no information other than the surface distribution. It contained the same $\mathrm{S}$ range as at the surface. In contrast to Figure $2 b$, Figure $3 b$ shows a general increase in salinity from north to south. Maximum salinities were found at the perimeter of the Antilles Current. This feature will be discussed in connection with Figure 4.

The density indices resulting from these $t$ and $S$ distributions (Figs $3 a, 3 b$ ) are given in Figure 3c, which demonstrates the horizontal homogeneity of the water north of the convergence. The convergence itself was marked by density index decrease from $\sigma$ $(\mathrm{t}, \mathrm{S})=25.9$ to $\sigma(\mathrm{t}, \mathrm{S})=25.4$. South of the convergence, the density continued to decrease. How far the closed density index lines south of the convergence between $60^{\circ} \mathrm{W}$ to $64^{\circ} \mathrm{W}$ indicated eddy-like circulation cannot be indicated by this data set. Elevations of the thermocline due to internal waves (Figs 4,$5 ; 6$ ) may also be a reason.

\section{Vertical $t, S$, and $\sigma(t, S)$ distribution}

To give an idea of the vertical distribution of the water masses described above, two of the numerous North-South and East-West hydrographic sections are reproduced here. 


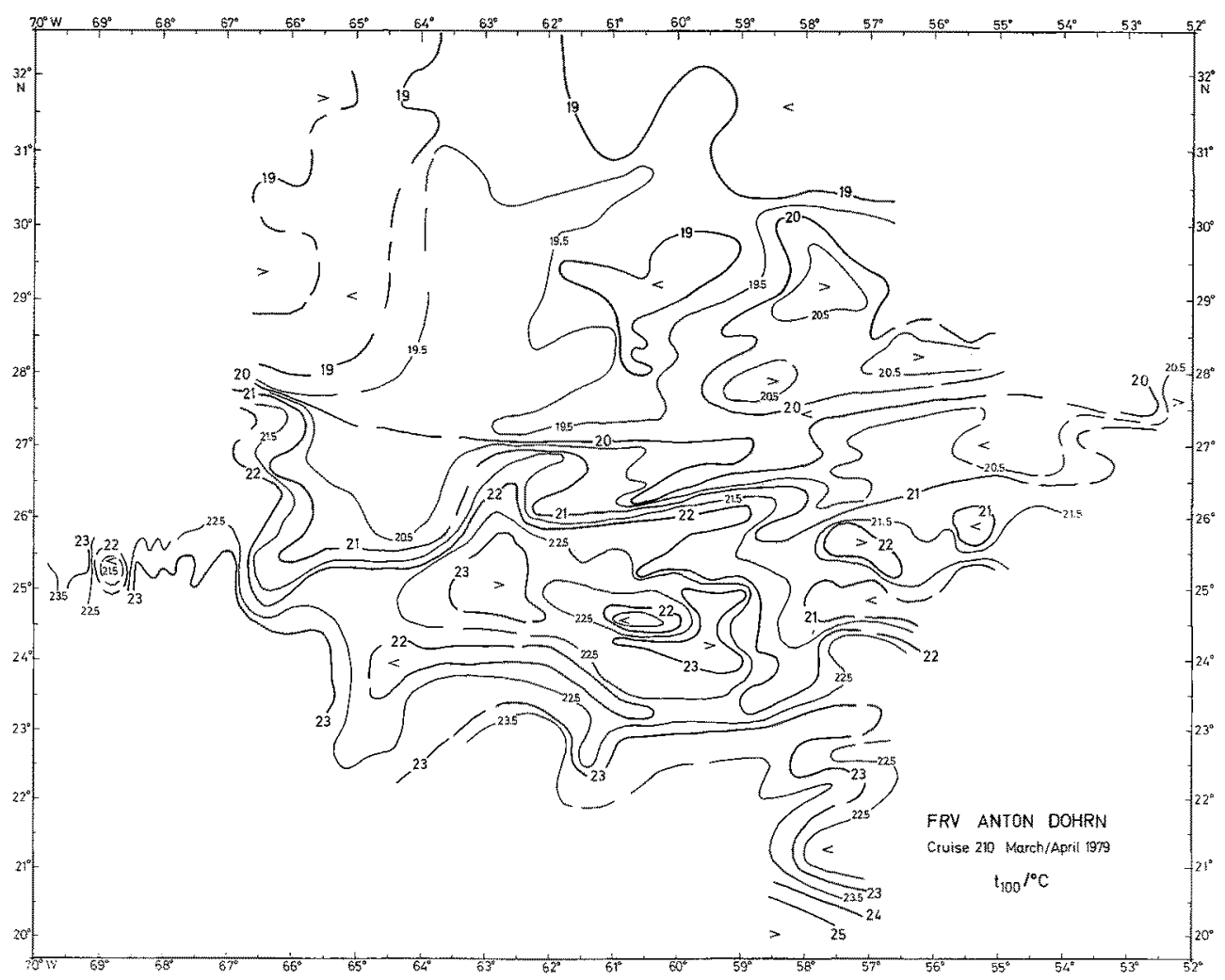

Fig. 3a. Temperature distribution in $100 \mathrm{~m}$ depth

Figure 4 shows the longest North-South section containing Stations 72 to 111 in the central part of the area investigated, and Figure 5 the East-West section with Stations 162 to 191 and, after interpolation, Stations 213 to 227 . The other sections, not shown, were of the same general hydrographic structure.

Although exact vertical salinity and density computations were compilable for the CTD stations only (station numbers given in the headings of Figs 4 and 5), construction of the salinity and density index sections was possible due to the strong $\mathrm{t}-\mathrm{S}$ correlation for $\mathrm{t}<18{ }^{\circ} \mathrm{C}$ (Fig. 7). For higher temperatures, the $\mathrm{t}-\mathrm{S}$ correlation between neighbouring stations were interpolated. (This was also true for the Figs $2 b, c$ and $3 b, c$.)

As already mentioned, in the area north of the convergence vertically homogeneous water was found down to $150 \mathrm{~m}$. Downwards, this northern Sargasso Sea surface water was followed by the "18 degree" water $\left[t=(18 \pm 1)^{\circ} \mathrm{C}, \mathrm{S}=(36.5 \pm 0.3) \times 10^{-3}\right.$; Istoshin, 19611 , which was the intermediate layer of the whole Sargasso Sea area investigated in a depth range of $200 \mathrm{~m}$ to $400 \mathrm{~m}$ (Figs 4,5 ). Wedge-shaped, it diminishes from north to south. Beneath, the "upper thermocline" $\left(12^{\circ} \mathrm{C}\right.$ to $17^{\circ} \mathrm{C}$; Worthington, 1976) went down to $700 \mathrm{~m}$ depth. In the southern parts of the sections, the warmed-up southern Sargasso Sea surface water was vertically homogeneous down to about $100 \mathrm{~m}$ depth. The different 


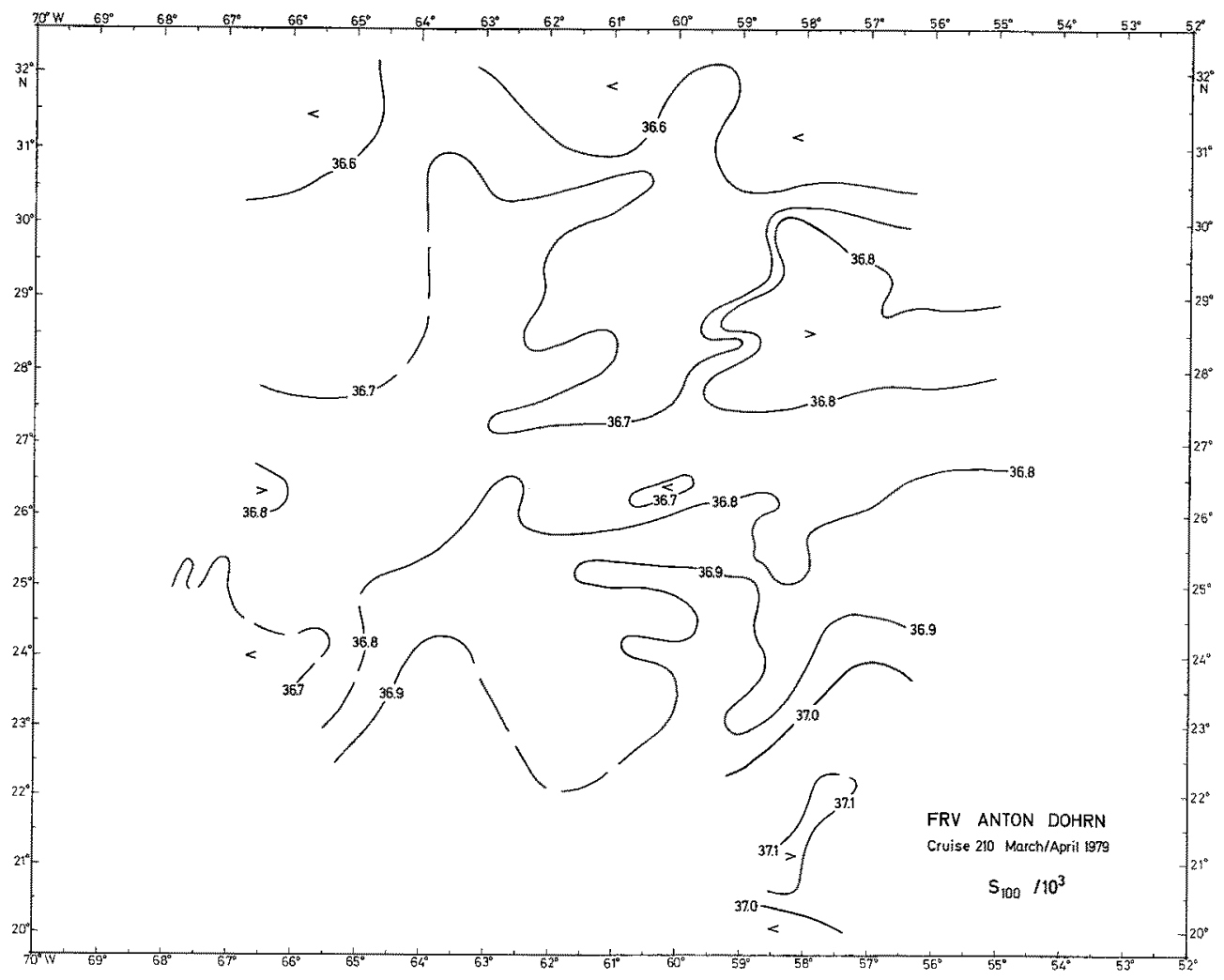

Fig. 3b. Salinity distribution in $100 \mathrm{~m}$ depth

surface waters were divided by the subtropical convergence consisting of water mixed from the northern and southern surface waters. At a depth of about $100 \mathrm{~m}$, this almost horizontal transition zone became the vertical thermocline dividing the southern surface layers from the "18 degree" water, the northern part of the subtropical thermocline (Defant, 1936).

In its middle or lower part, the subtropical thermocline encloses an intermediate maximum salinity layer. It originates from the general circulation of the warm water sphere of the Atlantic Ocean (Defant, 1936). Inside the convergence, the mixed surface water reaches depths of $150 \mathrm{~m}$ to $200 \mathrm{~m}$ by downwelling. In a depth layer corresponding to its density, it is transported into equatorial areas. As shown by Figures $2 b, 3 b, 4$, in the frontal area of the convergence zone, water of $36.8 \times 10^{-3}$ to $36.95 \times 10^{-3}$ was found. It went down to $100 \mathrm{~m}$ to $200 \mathrm{~m}$ at Station 90 . Following the subtropical thermocline, the intermediate layer of $10 \mathrm{~m}$ to $50 \mathrm{~m}$ thickness is not very well reproduced in Figures 4 and 5 . However, it preserved its $\mathrm{t}-\mathrm{S}$ correlation from the surface down to deeper depths, even at the southernmost stations [small peak in Fig. $7, \mathrm{t}=(19.7 \pm 0.1)^{\circ} \mathrm{C} ; \mathrm{S}<36.95 \times$ $10^{-3} \mathrm{~J}$. A lot of small scale layering, including some instabilities, had to be left out of the Figures. Perhaps the small, highly saline water masses $\left(\mathrm{S}>36.9 \times 10^{-3}\right)$ were con- 


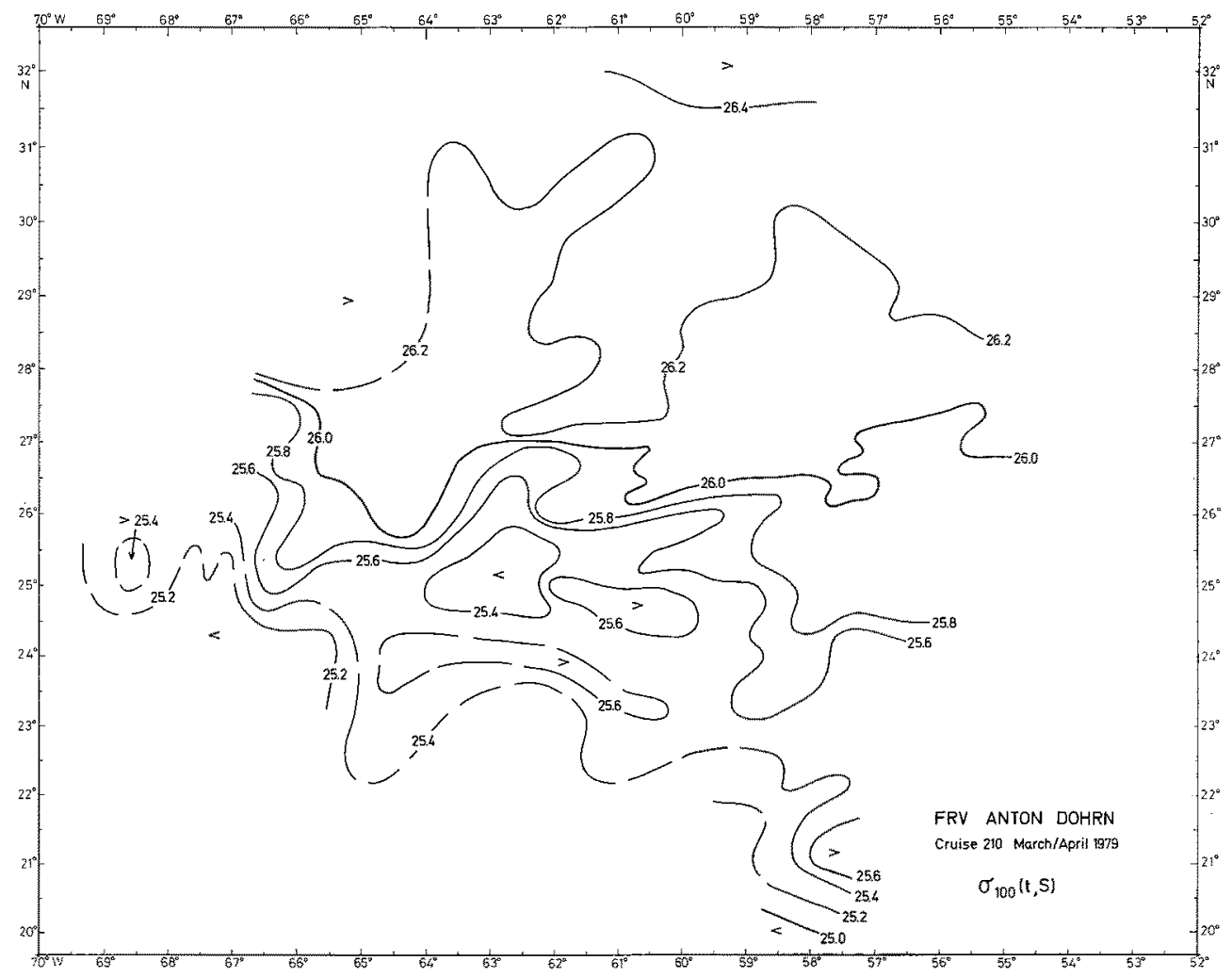

Fig. 3c. Density index distribution in $100 \mathrm{~m}$ depth

nected; for example, between Stations 92 and 96 (Fig. 4). As a consequence of salinity interpolation between the CTD stations, this question is open. The small, highly saline water masses may have had their origin in intrusions of southeastern surface water with higher salinity (Fig. 2b) into the mixed surface water. Incidently, considering their shape and the area of existence, the highly saline water masses should be named "lensis anguillaris".

Only in the section given in Figure 4 was a second intermediate salinity layer found south of Station 96 . Taking into account the Figures $2 \mathrm{~b}$ and $3 \mathrm{~b}$, this intermediate layer can be interpreted as southern surface water with salinities horizontally increasing in southeastern directions. It was overlaid by warmer, and less saline, surface water from the perimeter of the Antilles Current.

All sections crossing the convergence showed vertical displacements of the isolines beneath the frontal zone. The "18 degree" water was displaced to greater depths. A more or less thick layer of downwelled mixed surface water lay between the southern surface water and the "18 degree" water. The horizontal scale of $100 \mathrm{~km}$ to $150 \mathrm{~km}$ and the layer thickening of up to $100 \mathrm{~m}$ corresponded very well with the magnitudes Katz (1969) reported from his measurements (at the northwestern edge of the charts given here). 


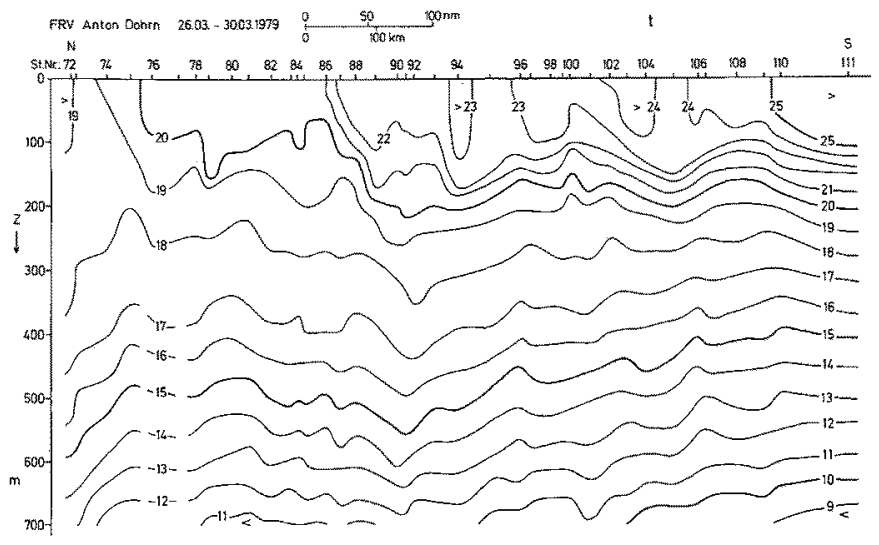

$\$$

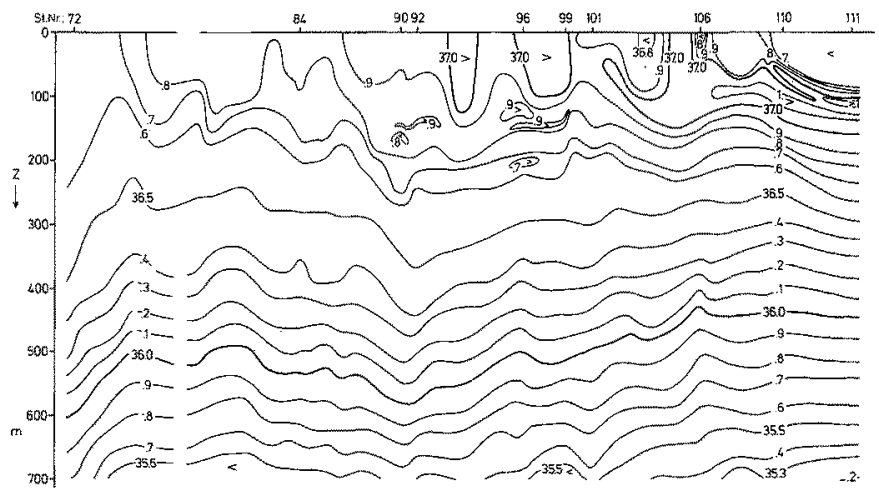

$\sigma$

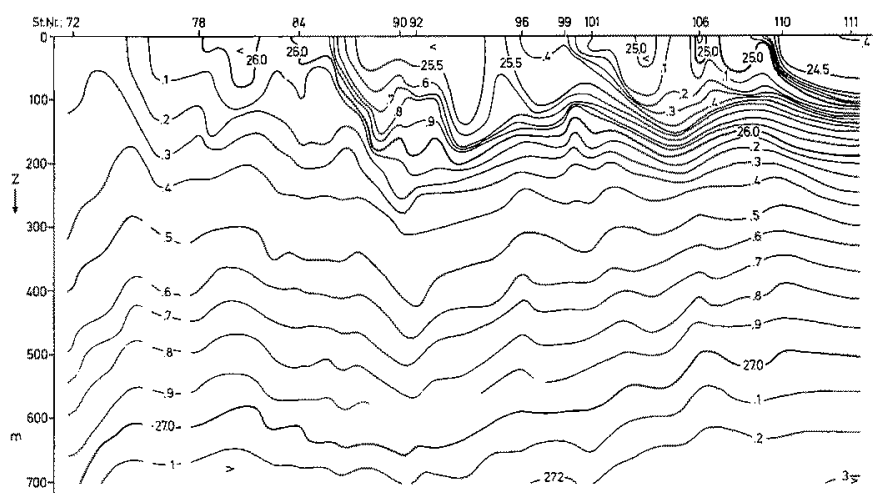

Fig. 4. North-South section (temperature, salinity, density index) 

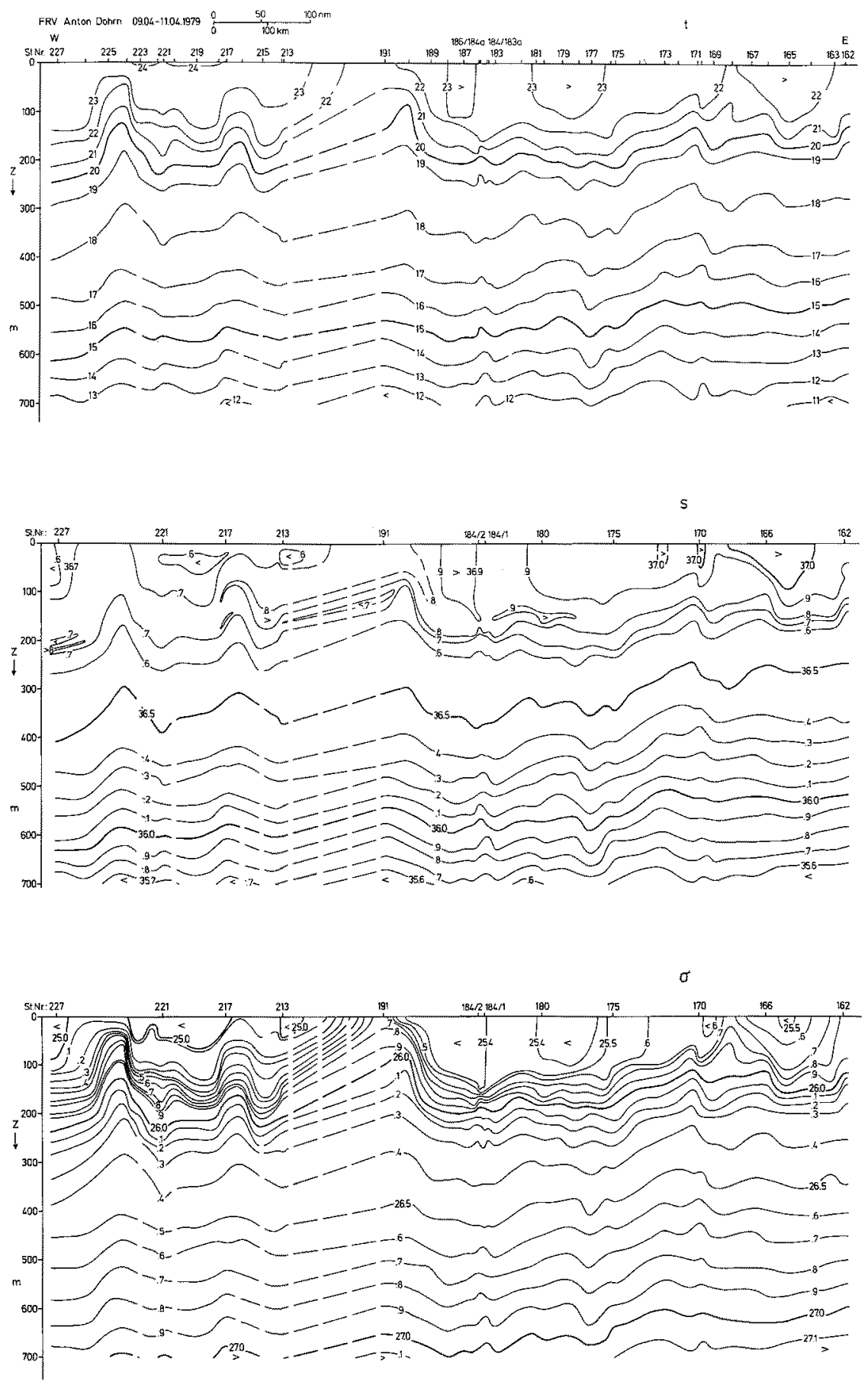

Fig. 5. East-West section (temperature, salinity, density index) 
Besides that, a lot of internal motion was common to all sections. With horizontal scales of $10 \mathrm{~km}$ to $100 \mathrm{~km}$, the isoline depths changed by up to $50 \mathrm{~m}$. In addition to such striking features as the eddy discussed (Fig. 5, westernmost part), the vertical displacements of the transition zone beneath the surface layers (Figs 4,5$)$ should have some influence upon the Anguilla larvae found in the vicinity of the convergence zone. The vertical isoline meandering was in the same magnitude as the vertical day-night migration of the largest 0-group larvae (Schoth \& Tesch, 1982). The movements of the internal waves may stop, hinder, or accelerate larval migration.

An attempt was made to obtain a clear picture of the main layering. From a southwestern standpoint (from $225^{\circ}$ to $45^{\circ}$ ) one looks into the depths of the density index. isolines 25.6 and 26.2 in Figure 6. The smoothed track of "Anton Dohrn" (thick line), similar to that of Figure 1, is coordinated to the framing chart grid, and gives the surface of the tilted density index sections. The depth scales for all stations are tilted corresponding to the direction of view. The East-West section (Stations 162 to 191) is given in the upper part of Figure 6. (Otherwise, the North-South sections - in part - would not be recognizable.)

The (upper) 25.6 isoline nearly corresponded to the frontal zone and to the upper border of the subtropical thermocline. The (lower) 26.2 isoline was only a little apart from the upper border of the "18 degree" water. Thus, the layer between both isolines

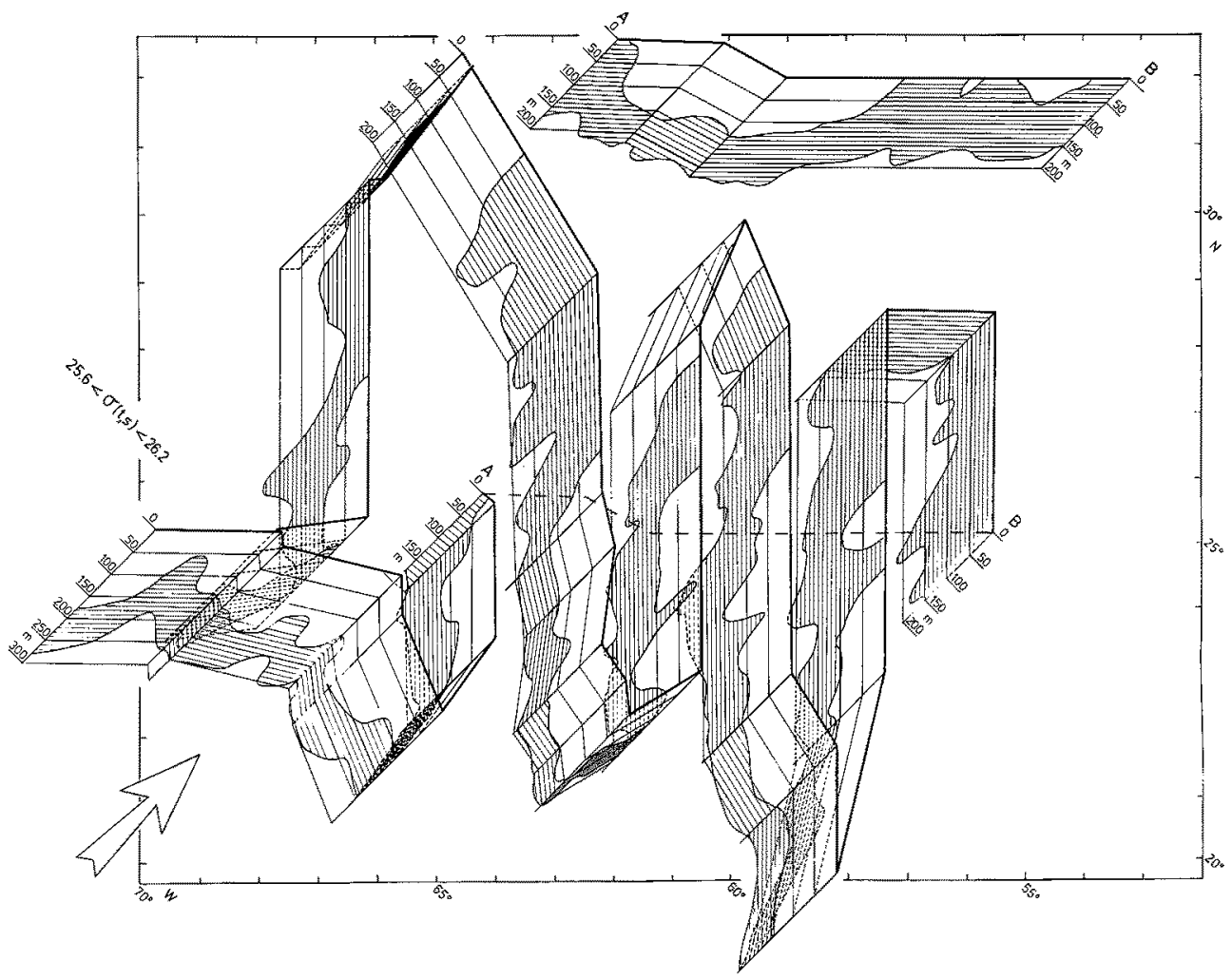

Fig. 6. Main layering, indicated by the density index isolines 25.6 and 26.2 
represented the convergence area and the subtropical thermocline. The layer is hatched in Figure 6. On the other hand, the depth of the 25.6 isoline gave the thickness of the generally nearly vertical homogeneous surface layer. From the features discussed, the vertical meandering and deepening of the isolines just to the south of and beneath the frontal zone, can be seen very well in Figure 6.
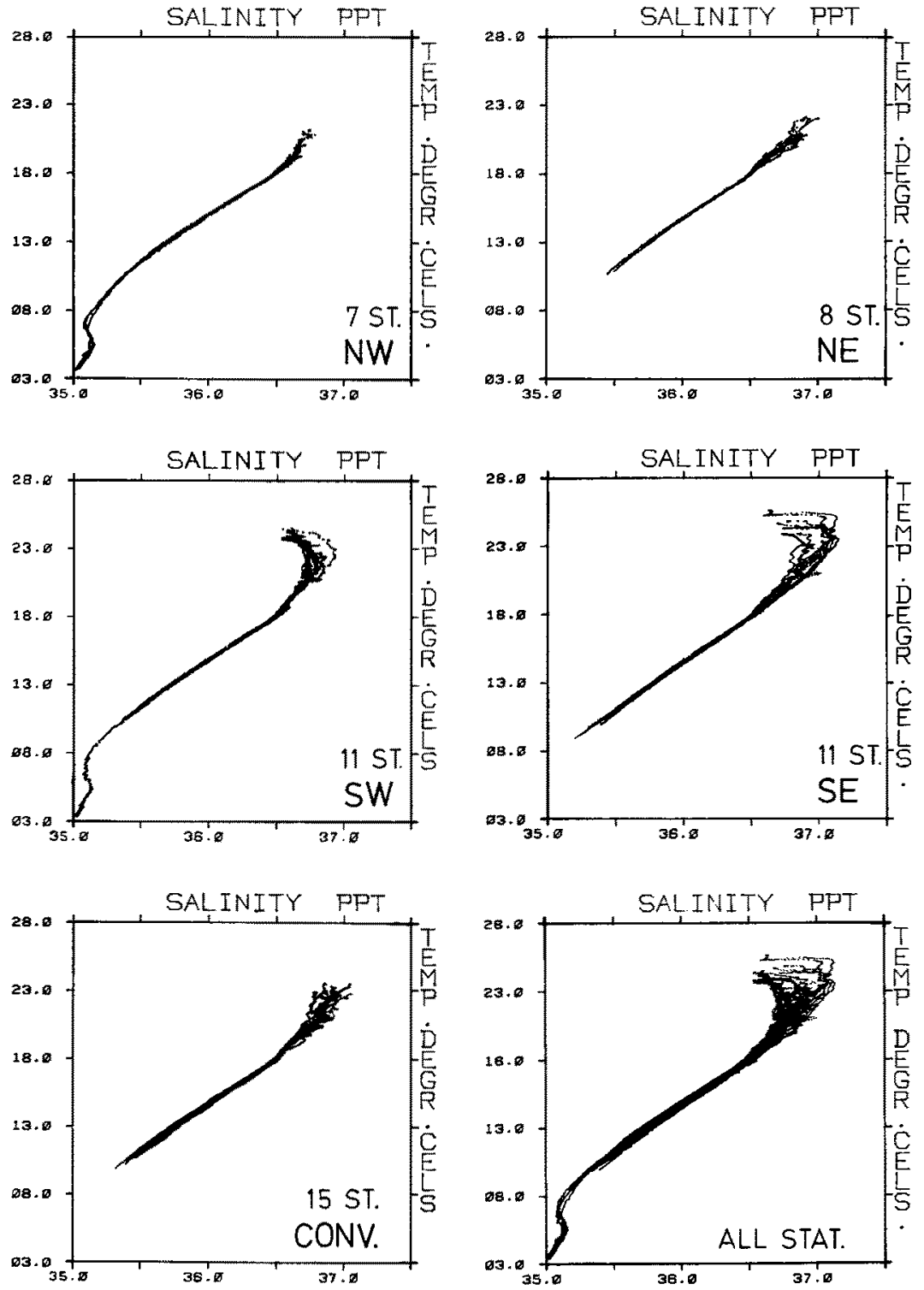

Fig. 7. t-S correlations for the areas: NW: North of $27.0^{\circ} \mathrm{N}$, West of $62.5^{\circ} \mathrm{W} ; 7$ stations; NE: North of $26.0^{\circ} \mathrm{N}$, East of $60.0^{\circ} \mathrm{W} ; 8$ stations; SW: South of $27.0^{\circ} \mathrm{N}$, West of $64.5^{\circ} \mathrm{W} ; 11$ stations; SE: South of $24.0^{\circ} \mathrm{N}$, East of $62.5^{\circ} \mathrm{W}$; 11 stations; CONV.: between $24.0^{\circ} \mathrm{N}$ and $26.0^{\circ} \mathrm{N}$, East of $64.5^{\circ} \mathrm{W} ; 15$ stations; ALL STAT.: stations of the areas above combined 


\section{t-S correlations}

The $\mathrm{t}-\mathrm{S}$ correlations of the 59 CTD stations are given in Figure 7. As already mentioned, the $\mathrm{t}-\mathrm{S}$ correlation below $19^{\circ} \mathrm{C}$ is nearly the same for all stations. However, small differences are systematic.

The longitudinal and latitudinal gaps are for better separation, the restriction of the "convergence" area to $64.5^{\circ} \mathrm{W}$ depends upon the strong eddy structures observed westwards in the corresponding longitudinal range. They could have had a different correlation.

On the one hand, Figure 7 presents the very different characteristics of the surface waters; on the other hand, for each of the four regions the small differences of the deeper water masses are remarkable. Combined, the regions NW, NE, and SW result in the relatively narrow upper part (lower salinity for a given temperature) of the graph in "ALL STAT.". The region SE represents the lower half of the combined graph. The stations of the region "convergence" are the link between the SE and the other 3 regions, not only for the surface water, but also for the water masses down to $700 \mathrm{~m}$. Especially for the "18 degree" water and beneath, the rule seems to be: the more the station lies to the southeast of the area investigated, the higher the salinity is for given temperatures (maximum difference: $0.15 \times 10^{-3}$ ). This rule includes the $\mathrm{t}-\mathrm{S}$ correlation given by Katz (1969). His positions at the northwestern edge of the charts used here had nearly the same temperature-salinity relation as the northwestern "Anton Dohrn" stations.

According to the rule, crossing of the salinity and density index isolines with the isotherms was observed mainly in the south of the convergence area during the construction of the sections.

\section{Dynamic computations}

Keeping in mind all the limitations of the dynamic method (only horizontal frictionless stationary motion, increasing inaccuracies with decreasing latitude), this method is used to obtain the magnitudes of horizontal current components in the Sargasso Sea. The dynamic anomalies were computed from the CTD stations. The interpolation of the XBT measurements was omitted owing to summation of even very small variations. The largest common depth was 650 dbar. Apart from southwestern edges (influence of the Antilles Current), the relative differences of the anomalies between $650 \mathrm{dbar}$ and 1000 dbar - one of the depths usually preferred - can be considered as small. For instance, related to $650 \mathrm{dbar}$ and to $1000 \mathrm{dbar}$, the surface current difference was less than $2 \%$ between Stations 213 and 268. In addition, the main differences in the anomalies occurred between $100 \mathrm{dbar}$ and $300 \mathrm{dbar}$ - corresponding to the dynamic computations of Bubnov \& Fedorov (1979).

Owing to the fact that the maximum larval catches came from a range of preferred depth between $75 \mathrm{~m}$ and $150 \mathrm{~m}$, the dynamic topography of the surface was reduced to 100 dbar. Figure 8 shows the dynamic topography of 100 dbar relative to $650 \mathrm{dbar}$. The geostrophic current flows parallel to the isolines of topography. In Figure 8, current directions are given by arrows. As the CTD grid taken as a basis is of large distances, one should be careful not to read - as is usual - the geostrophic velocities from the isoline distances. The numbers alongside the arrows in Figure 8 give the computed (mean) current velocities in $\mathrm{cm} \mathrm{s}^{-1}$ perpendicular to the corresponding pairs of the CTD stations 
(dots in Fig. 8). The arrows only have been tilted in the directions parallel to the isolines. Thus, Figure 8 provides an idea of the horizontal water movement of the 100 dbar layer relative to the $650 \mathrm{dbar}$ layer.

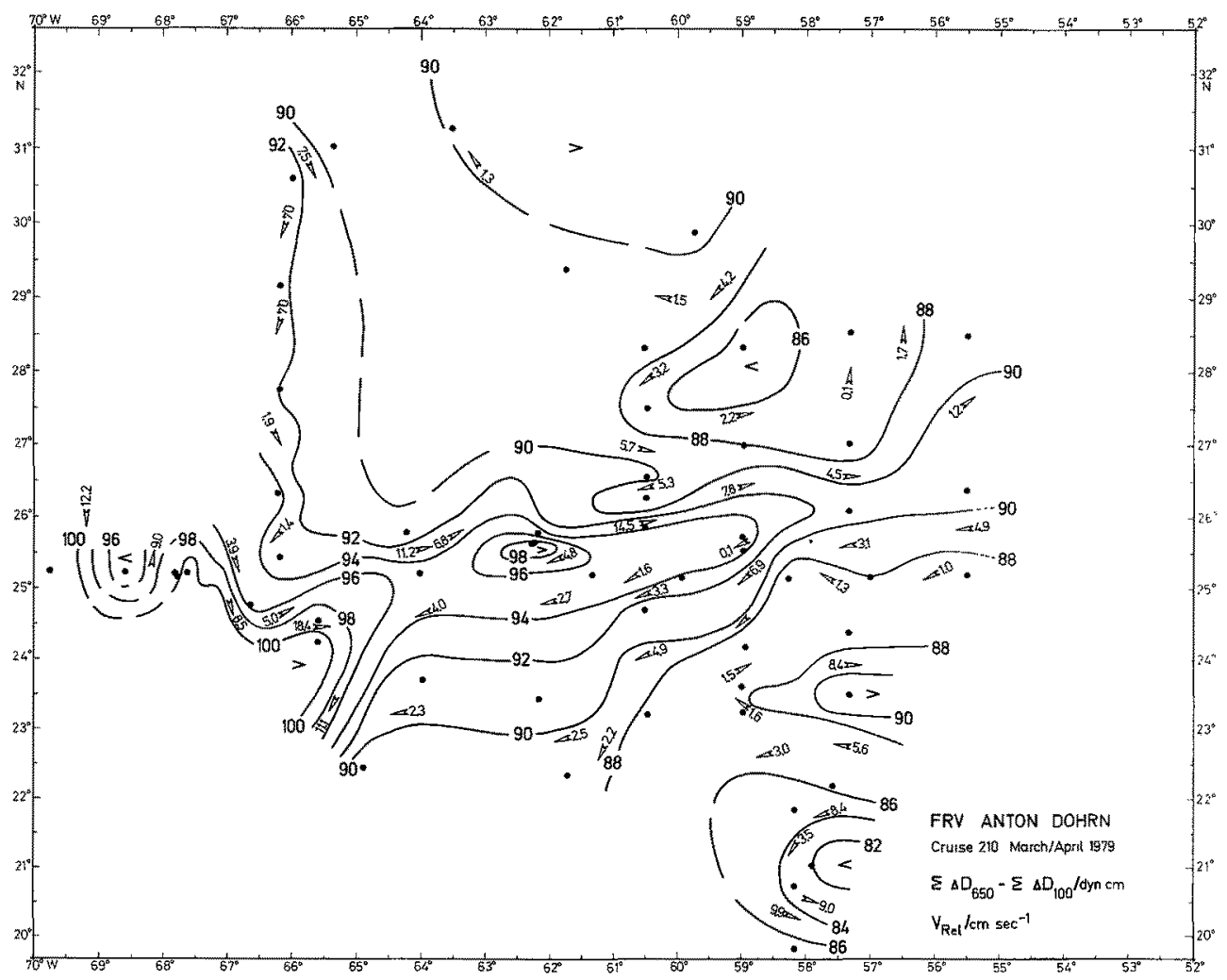

Fig. 8. Dynamic topography of 100 dbar relative to 650 dbar, and corresponding geostrophic currents

Although based upon a rough grid of about 60 stations - in the topography, the convergence area was stressed by a ridge with relatively steep slopes. It separated the northern and southern areas containing weaker gradients. In the northern area, the current velocities were in the magnitude of nearly $0 \mathrm{~cm} \mathrm{~s}^{-1}$ to $5 \mathrm{~cm} \mathrm{~s}^{-1}$, generally in western directions. The northern part of the frontal zone moved to the east with up to $14 \mathrm{~cm} \mathrm{~s}^{-1}$. The southern part of the convergence area had western currents of up to $7 \mathrm{~cm}$ $\mathrm{s}^{-1}$. The transition into the southern area is less abrupt than into the northern area. In larger parts of the southern area, the 100 dbar level showed motion into western directions also with $1.6 \mathrm{~cm} \mathrm{~s}^{-1}$ to $7.5 \mathrm{~cm} \mathrm{~s}^{-1}$. Figure 8 gives some current alternations east of $61^{\circ} \mathrm{W}$ in both areas. Perhaps they only exist fictitiously owing to the nonsynoptic data. Nevertheless, the northern one was of slower motion $\left(<3.5 \mathrm{~cm} \mathrm{~s}^{-1}\right)$ than the two southern features (up to $10 \mathrm{~cm} \mathrm{~s}^{-1}$ ).

Maybe denser CTD measurements in the frontal zone would produce much higher 
velocities. Katz (1969) computed more than $60 \mathrm{~cm} \mathrm{~s}^{-1}$ for the northern frontal current, which agreed with his GEK measurements.

The highest current velocity, computed from a couple of "Anton Dohrn" CTD stations, lay in the area where Beckerle (1972) supposed a stable eddy street to exist. Between Stations 211 and 213 the velocity was $18.9 \mathrm{~cm} \mathrm{~s}^{-1}$ coinciding with the $25 \mathrm{~cm} \mathrm{~s}^{-1}$ to $30 \mathrm{~cm} \mathrm{~s}^{-1}$ geostrophic orbital velocity (relative to $2000 \mathrm{~m}$ ) reported by Bubnov \& Fedorov (1979). Perhaps these stations lay in an anticyclonic eddy.

\section{Conclusions regarding eel larvae catches}

During the period under study, the part of the Sargasso Sea investigated was characterized by northern and southern surface waters divided by the convergence area including frontal zones. In the whole area, the "18 degree" water was found beneath the main (subtropic) thermocline, which included the subtropic intermediate maximum salinity layer. The conservation of the $t-S$ correlation of the frontal zone water in the intermediate layer and the systematic slight $t-S$ differences for the deeper water seem to have no influence upon the eel larvae. On the one hand, the maximum catches were made between $175 \mathrm{~m}$ and $50 \mathrm{~m}$; that means, the eel larvae live more or less in the lower half of the surface layer. On the other hand, the catches were restricted to the convergence area, predominantly to its northern part and the frontal zones. Perhaps the frontal zones belong to the area stimulating spawning of the migrating adult eels. The eddy structures in the southwestern perimeter of the area investigated could have the same influence upon the adult eels, because larger numbers of larvae were collected in the northern vicinity of these features.

The different parts of the current field seem unable to bring the larvae into preferred directions. The (geostrophic) current velocities are too low. Let us consider newly-born larvae inside the northern frontal current. Within 7 days, the animals will be transported about $300 \mathrm{~km}$ to the East if they stay during the whole period in the core of the current with a constant velocity of $50 \mathrm{~cm} \mathrm{~s}^{-1}$. That means, they will be transported through half the area of the larval catches. It seems to be a random process of birthplace if the currents cause acceleration or hindrance to the animals in their struggle to migrate to America or Europe; however, both the extent of acceleration and prevention are slight when compared with the distance the larvae have to travel. During future investigations in the convergence area, narrow depth ranges should be trawled with opening and closing nets associated with very dense CTD measurements. So that, by a possible correlation of larval quantity and water density, the spawning layer might become recognizable, a step which might then reveal the answer to our Bermuda phenomena of being able to catch larvae without catching adults.

Acknowledgements: I wish to thank Professor Dr. Weidemann for his helpful discussions; Mrs. Petersitzke for bringing my experimental English into readable form; Mr. Kanje for preparing the figures according to all my special wishes; and Mr. Stein and Mr. Cornus for their patience while I tried to "play" with their computer.

\section{LITERATURE CITED}

Beckerle, J. C., 1972. Eddy circulation patterns in the Sargasso Sea. - Rapp. Proc.-v. Réun. Cons. int. Explor. Mer. 162, 264-275. 
Bubnov, V. A. \& Fedorov, K. N., 1979. An anticyclonic eddy in the Sargasso Sea. - Polymode News $68,1-2$.

Defant, A., 1936. Schichtung und Zirkulation des Atlantischen Ozeans. Die Troposphäre. - Wiss. Ergebn. dt. atlant. Exped. "Meteor" 6 (1), 289-411.

Istoshin, Yu. V., 1961. Formative area of "eighteen degree" water in the Sargasso Sea. Okeanologiya 1, 600-607 (Russ.) (Transl.: Deep Sea Res. 9, 384-390).

Katz, E. J., 1969. Further study of a front in the Sargasso Sea. - Tellus 21, 259-269.

Schoth, M. \& Tesch, F. W., 1982. Spatial distribution of 0-group eel larvae (Anguilla sp.) in the Sargasso Sea. - Helgol. Meeresunters. 35, 309-320.

Tesch, F. W., 1982. The Sargasso Sea Eel Expedition 1979. - Helgol. Meeresunters. 35, $263-277$.

Worthington, L. V., 1976. On the North Atlantic circulation. - Johns Hopkins oceanogr. Stud. 6, $1-110$. 